\title{
Comparative Analyses of Inflammatory Response and Tissue Integration of 14 Hyaluronic Acid-Based Fillers in Mini Pigs
}

\author{
Min-Seo Choi ${ }^{1, *}$ \\ Seongsung Kwak (iD),2,* \\ Junhyung Kim ' \\ Mi-Sun Park' \\ Soo Min Ko (iD ${ }^{2}$ \\ Taehee Kim (iD ${ }^{2}$ \\ Da Som Jeong ${ }^{2}$ \\ Chang-Hoon Rhee iD $^{3}$ \\ Gi-Hyeok Yang ${ }^{1,3}$ \\ Woo-Chan Son ${ }^{2}$ \\ Won-Ho Kang (iD) \\ 'Gwanggyo R\&D Center, Medytox Inc, \\ Suwon-si, Gyeonggi-do, Republic of \\ Korea; ${ }^{2}$ Department of Medical Science, \\ Asan Medical Institute of Convergence \\ Science and Technology, Asan Medical \\ Center, University of Ulsan College of \\ Medicine, Songpa-gu, Seoul, Republic of \\ Korea; ${ }^{3}$ Osong R\&D Center, Medytox \\ Inc, Cheongju-si, Chungcheongbuk-do, \\ Republic of Korea \\ *These authors contributed equally to \\ this work
}

Correspondence: Won-Ho Kang Non-Clinical Development Department, Gwanggyo R\&D Center, Medytox Inc, I I Central Town-Ro, Yeongtong-Gu, Suwon-si, Gyeonggi-do, 16506, Republic of Korea

Tel +82 3I 80658243

Fax +82 31 80658232

Email whkang@medytox.com

Woo-Chan Son

Department of Medical Science, Asan Medical Institute of Convergence Science and Technology, Asan Medical Center, University of Ulsan College of Medicine, 88 Olympic-Ro 43-Gil, Songpa-gu, Seoul, 05505, Republic of Korea

Tel +82 230104051

Fax +82 230104099

Email wcson@amc.seoul.kr
Purpose: Hyaluronic acid (HA)-based dermal fillers have been approved for various clinical indications, both cosmetic and medical. Previous studies that have assessed the performance of HA dermal fillers have primarily focused on evaluating filler durability, and only a few have studied their distribution within the tissues. The present study aimed to compare tissue integration of various types of HA dermal fillers having different clinical indications and varying injection depths.

Methods: To examine the local inflammatory response and distribution pattern of $14 \mathrm{HA}$ dermal fillers (six Neuramis [NEU], one Belotero [BEL], three Juvéderm [JUV], and four Restylane [RES]), each product was injected intradermally and subcutaneously at the backs of two male miniature pigs. Histopathological evaluation and visual examination of the tissue sections were conducted 1 and 4 weeks after injection.

Results: Mean inflammatory cell infiltration scores tended to be lower in response to fillers from the NEU and BEL series than to those from the JUV and RES series after intradermal and subcutaneous injection. Furthermore, the inflammatory response to fillers with higher physicochemical properties specifically designed for injection into deeper layers of the skin tended to be slightly higher than those designated for injection into more superficial layers. There was no significant difference in tissue integration according to clinical indication and injection depth, although fillers from the NEU and BEL series exhibited better tissue integration than those from the JUV and RES series.

Conclusion: Our findings not only suggest that the local inflammatory response and tissue integration differ across HA dermal filler products, but also that these parameters could vary according to the recommended clinical indication and injection depth of the products.

Keywords: histopathology, inflammatory response, HA filler, soft tissue augmentation, tissue integration

\section{Introduction}

Hyaluronic acid (HA)-based dermal filler is a gel-type substance that is injected under the skin to treat signs of aging. HA dermal fillers function by filling the spaces within the tissue, and lifting and shaping the skin surface. The hydrophilic properties of the HA compound allow the dermal filler to attract large amounts of water, thereby ensuring hydration and volumization. ${ }^{1}$ HA dermal fillers are easy to inject, lack immunogenicity, and have good biocompatibility profiles. ${ }^{2}$ Their high affinity for water molecules and absence of any major adverse reactions make them appropriate candidates for creating volume in the skin and soft tissues. 
Aside from being a suitable dermal filler, the biocompatibility of HA makes it an ideal agent for other medical applications that includes tissue engineering, cancer biology, wound healing, and drug-delivery systems. ${ }^{3-5}$ In its natural form, the HA polymer is subjected to enzymatic degradation which quickly breaks down the macromolecule, resulting in a half-life of 24 hours in the skin. ${ }^{6}$ Different cross-linking technologies using chemical agents such as 1,4-butanediol diglycidyl ether (BDDE), divinyl sulfone, poly(ethylene glycol) diglycidyl ether, and more recently bis-( $\beta$ isocyanatoethyl) disulphide, have been developed to generate cross-linked HA hydrogels that have increased resistance to biodegradation and enhanced biological performance as implantable devices or biomaterials. ${ }^{7-9}$ In the field of aesthetic medicine, duration and stability of HA dermal fillers after implantation into the tissues is very important. BDDE is the predominant cross-linker used to stabilize the majority of currently marketed HA dermal fillers as it has received approval from various regulatory bodies due to its favorable stability and proven safety record. ${ }^{10}$ BDDE cross-linked HA dermal fillers have been shown to achieve a safe clinical duration of 1 year or more. ${ }^{10}$

Since the early 2000s, a variety of HA dermal fillers and other forms of HA gel fillers have been approved for a wide range of indications, including both cosmetic and medical use, such as the correction of wrinkles and folds, volume enhancement of cheeks and lips, and treatment of various age-related diseases. ${ }^{11}$ Currently marketed HA dermal fillers differ substantially in their physicochemical properties and hardness of gel, and in general, each filler product in a single series has a specific clinical indication for targeting specific tissues. For example, HA dermal fillers have been specifically developed for injection into deeper layers of the skin, such as the subcutaneous and supraperiosteal zones, and are commonly used for the correction of facial volume. In contrast, HA dermal fillers that have been developed for more superficial injection are more suitable for targeting fine superficial wrinkles, and/or restoring the skin hydrobalance. ${ }^{12}$

Although numerous pre-clinical and clinical studies have been conducted to assess the performance of various types of commercialized HA dermal fillers and evaluate their effectiveness, most of the studies have primarily focused on the evaluation of durability and/or swelling capacity of the fillers. ${ }^{13-15}$ However, durability only assesses the in vivo residence time by measuring the residual volume at the injection site, and does not explore or account for other variables of filler performance or clinical behavior. Therefore, drawing conclusions about the overall performance of HA dermal fillers based on the evaluation of durability is inappropriate. More recently, there has been a growing interest in the evaluation of tissue integration of HA dermal fillers. The terms "tissue integration" and "biointegration" are synonymous and refer to the "pattern of distribution within the biological tissue and, specifically, the way the filler material entangles itself in dermal fibers". ${ }^{16}$ In clinical use, HA dermal fillers have been reported to be associated with problems relating to textural changes, such as superficial beading and lumping. ${ }^{17}$ Hence, it is particularly important to study tissue integration in detail, especially when characterizing the overall performance and safety of novel HA dermal fillers that are still under development. To date, only a few studies using four or fewer products have reported the distribution pattern of HA dermal fillers and their integration within the tissue. ${ }^{16-20}$

This study aimed to compare the tissue integration of a wide range of HA dermal fillers with different clinical indications and injection depths. We examined the local inflammatory response and distribution pattern of 14 commercialized HA dermal fillers after intradermal and subcutaneous injection in miniature pigs (mini pigs).

\section{Materials and Methods}

This study was conducted at the animal facility of KNOTUS Co., Ltd. (Incheon, Republic of Korea) in accordance with the Laboratory Animal Act of Korea (Act No. 15278). Prior to the initiation of the study, all experimental protocols were approved by the Institutional Animal Care and Use Committee (IACUC) of KNOTUS Co., Ltd., following the IACUC guidelines proposed by the Ministry of Food and Drug Safety, Republic of Korea: Subcutaneous study (Approval No.: 18-KE-439) and intradermal study (Approval No.: 18-KE-439-1) in mini pigs.

\section{Animals}

Two healthy six-month-old male mini pigs (Sus scrofa domestica) were purchased from APURES Co., Ltd. (Gyeonggi-do, Republic of Korea), and each animal was housed in a stainless steel cage (width, $120 \mathrm{~cm} \times$ length, $170 \mathrm{~cm} \times$ height, $170 \mathrm{~cm}$ ). The animals were kept in an environment with a 12-h light/dark cycle, a controlled temperature of $23 \pm 3^{\circ} \mathrm{C}$, and a relative humidity of $55 \pm$ $15 \%$. The animals had free access to both food and water.

\section{HA Fillers}

The following BDDE cross-linked 14 HA dermal fillers were used in this study: Neuramis Volume Lidocaine (NEU-VL; 
Medytox Inc., Seoul, Republic of Korea), Neuramis Deep Lidocaine (NEU-DL; Medytox Inc.), Neuramis Deep (NEUD; Medytox Inc.), Neuramis Lidocaine (NEU-L; Medytox Inc.), Neuramis Light Lidocaine (NEU-LL; Medytox Inc.), Neuramis Skin Lidocaine (NEU-SL; Medytox Inc.), Belotero Volume Lidocaine (BEL-VL; Merz Pharma ceuticals GmbH, Frankfurt, Germany), Juvéderm VOLUMA with Lidocaine (JUV-VL; Allergan Inc., Pringy, France), Juvéderm ULTRA PLUS XC (JUV-U1; Allergan Inc.), Juvéderm ULTRA XC (JUV-U2; Allergan Inc.), Restylane LYFT with Lidocaine (RES-LL; Q-Med AB, Uppsala, Sweden), Restylane Lidocaine (RES-L; Q-Med AB), Restylane SKINBOOSTERS Vital Lidocaine (RES-S1; Q-Med AB), and Restylane SKINBOOSTERS Vital Light Lidocaine (RES-S2; Q-Med AB). To perform a fair comparison, all 14 HA dermal fillers were grouped into four categories based on similarities in clinical indication and target injection depth recommended by the respective manufacturer's instructions for use. ${ }^{21-34}$ The categories were as follows: (1) fillers intended for injection into the subcutaneous and/or supraperiosteal layer for the correction and restoration of facial volume; (2) fillers intended for injection into the midto-deep dermis and/or subcutaneous layer for the correction of moderate to severe facial folds and wrinkles; (3) fillers intended for injection into the dermis for the correction of folds and wrinkles on the lower face such as nasolabial folds; and (4) fillers intended for injection into the dermis for the correction of fine wrinkles and/or restoration of skin hydrobalance, and improvement of skin appearance and elasticity. There was some minor overlap of clinical indication and injection depth between a few of the fillers used. The description of each filler and category are found in Table 1.

\section{Experimental Design and Injection of Filler}

Each product was assigned to one of the 15 groups (the saline control being designated as group 1 and the 14 HA dermal fillers designated as groups 2 15) (Figure 1). Each filler was assigned an injection area of $5 \mathrm{~cm} \times 5 \mathrm{~cm}$ in the dorsum of the animal. Injections were made $2.5 \mathrm{~cm}$ apart to prevent potential interference between the sites. On day 0 , general anesthesia was induced by intravenous administration of $5 \mathrm{mg} / \mathrm{kg}$ tiletamine-zolazepam (Zoletil 50; Virbac, Carros, France) and $2.5 \mathrm{mg} / \mathrm{kg}$ xylazine (Rompun; Bayer AG, Leverkusen, Germany) prior to injection of filler. The products of groups $1 \sim 11$ were injected intradermally into four injection sites (0.2 $\mathrm{mL}$ per site) in the animal. On day 20 , the same animal was similarly injected with the products of groups 12 15; these four products were expected to degrade faster than the
Table I I4 HA Dermal Fillers Categorized into Four Groups Based on Their Approved Clinical Indications

\begin{tabular}{|l|c|}
\hline Clinical Indication and Depth of Injection $^{\dagger}$ & $\begin{array}{c}\text { HA Dermal } \\
\text { Filler }\end{array}$ \\
\hline $\begin{array}{l}\text { Correct and restore facial volume; subcutaneous } \\
\text { and/or supraperiosteal layer }\end{array}$ & $\begin{array}{c}\text { NEU-VL } \\
\text { BEL-VL } \\
\text { JUV-VL }\end{array}$ \\
\hline Correct moderate to severe facial folds and & NEU-DL \\
wrinkles; mid-to-deep dermis and/or subcutaneous & NEU-D \\
layer & RES-LL \\
& JUV-UI \\
\hline Correct folds and wrinkles on the lower face, such & NEU-L \\
as the NLFs; dermis & RES-L \\
& JUV-U2 \\
\hline Correct fine wrinkles and/or restore hydrobalance, & NEU-LL \\
improve skin appearance, and elasticity; dermis & NEU-SL \\
& RES-SI \\
& RES-S2 \\
\hline
\end{tabular}

Notes: ${ }^{\dagger}$ From the package insert.

Abbreviations: HA, hyaluronic acid; NLF, nasolabial fold.

others, and therefore, were injected closer to the necropsy date. The animals were anesthetized 4 weeks after the first injection, using the same method as that used for the previous injections, and were immediately sacrificed by exsanguination from the axillary artery and vein. Both the injected filler and the surrounding tissues were excised for histopathological analysis.

The same procedure was followed in a separate animal using subcutaneous injection. The two injection routes used in the present study were the same as those intended for clinical use of the products.

\section{Histological Evaluation}

Tissue samples were fixed in 10\% formalin and embedded in paraffin. Sections were stained with hematoxylin and eosin to evaluate tissue histology, and with Alcian blue to visualize the position, shape, and distribution of the injected HA dermal filler. The stained sections were viewed and imaged using an Olympus BX53 microscope (Olympus Corp., Tokyo, Japan).

The pathologist that was blinded to the treatments were provided with the tissue sections and evaluated both the local tissue integration and inflammatory responses to the HA dermal fillers.

The local inflammatory response was assessed in accordance with the histological evaluation system described in the ISO 10993-6 standard, ${ }^{35}$ with each of the four tissue samples (four injection sites) of each filler treatment being assigned a histology score of 0 (no response), 1 (minimal response), 2 


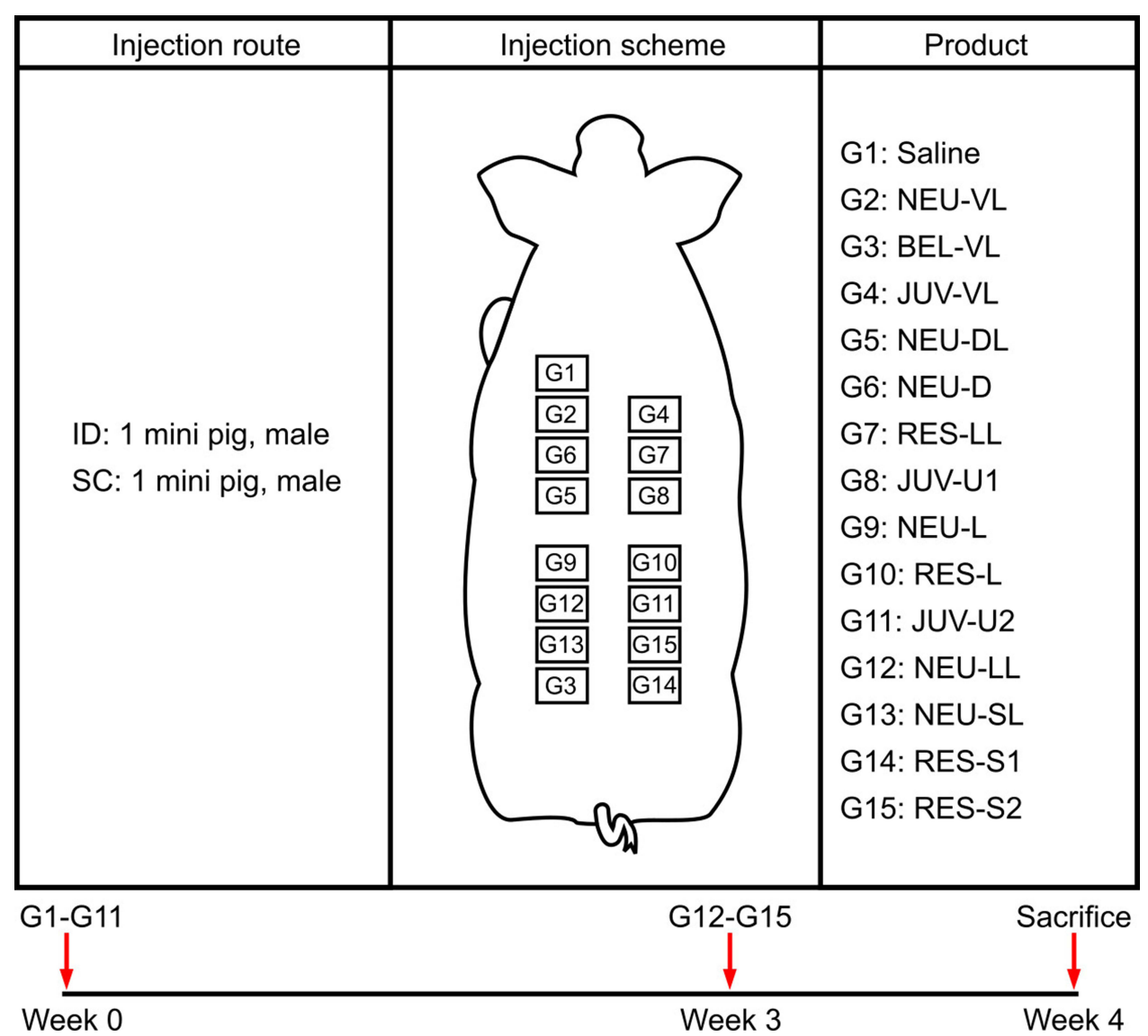

Figure I Experimental design. On day 0 (week 0), saline (control) and the products of G2 GI I (test groups) were each injected via intradermal (ID) and subcutaneous (SC) route into four injection sites $(0.2 \mathrm{~mL}$ per site) in miniature pigs. On day 20 (week 3 ), the products of GI2 GI5 were administered to designated sites in a similar manner. Abbreviations: ID, intradermal; SC, subcutaneous; G, group.

(mild response), 3 (moderate response), or 4 (severe response). The scores of the four tissue samples were combined to determine the average score for each filler treatment.

Tissue integration was assessed by a pathologist who was guided by the evaluation criteria described elsewhere. ${ }^{16,17,20}$ Briefly, the pathologist was given a description of the specific features that were considered to equate to either good tissue integration (homogeneity, even distribution across tissue section, and sufficient entanglement of filler within tissue fibers) or a lack of tissue integration (pooling, irregular distribution across tissue section, and minimal or no entanglement of filler within tissue fibers) which served as a guide for assessing this parameter.

\section{Statistical Analysis}

All statistical analyses were performed using GraphPad Prism 7.05 (GraphPad Software Inc., San Diego, CA, USA). The Mann-Whitney test was used to compare the mean inflammatory cell infiltration scores between the saline control group and filler groups, and for comparison across all filler groups according to clinical indication and injection depth. Statistical significance was set at $P<0.05$.

\section{Results}

\section{Histological Findings}

\section{Normal Saline}

Minimal macrophage and giant cell infiltration were observed after intradermal injection (Figure 2A). After subcutaneous injection, minimal hemorrhage was observed, although the skin appeared normal (Figure 3A). The injected saline was not visible in the Alcian blue-stained tissue sections (Figures 4A and 5A).

\section{NEU Series (NEU-VL, NEU-DL, NEU-D, NEU-L, NEU-LL, and NEU-SL)}

In most of the NEU series fillers, more severe local inflammatory responses were observed after intradermal injection than after subcutaneous injection. The local inflammatory responses after intradermal injection of 

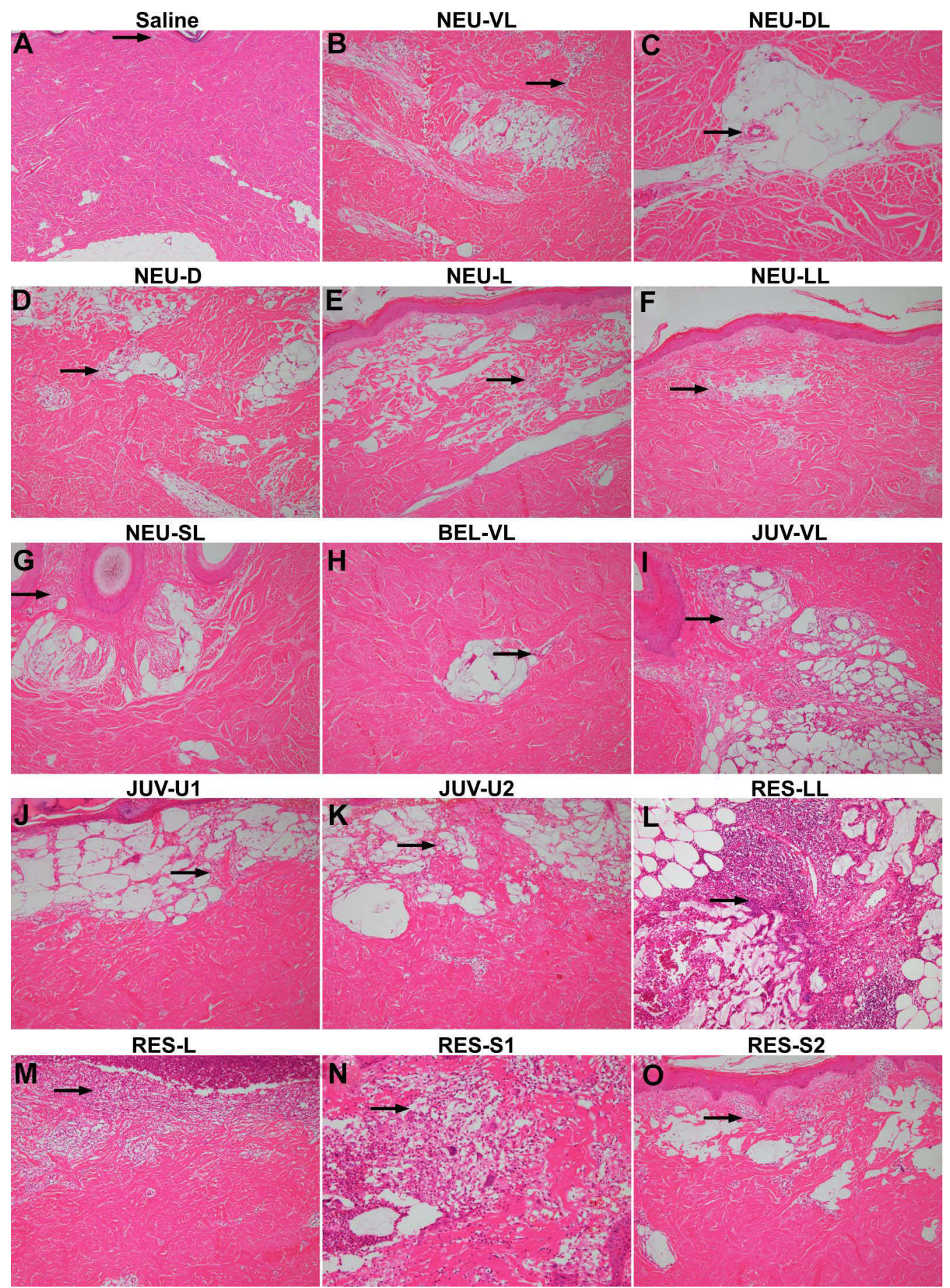

Figure 2 Hematoxylin and eosin staining at I and 4 weeks after intradermal injection of the saline control (A), NEU series (B-G), BEL-VL (H), JUV series (I-K), and RES series (L-O). Arrows indicate the location of the inflammatory cells. All images are shown at the same magnification $(\times 40)$.

the NEU series were as follows (Table 2 and Figure 2B$\mathrm{G})$ : NEU-VL, minimal macrophage and giant cell infiltration and moderate purulent inflammation; NEU-DL, minimal to mild macrophage and giant cell infiltration; NEU-D, minimal to moderate macrophage and giant cell infiltration and minimal purulent inflammation; NEU-L, minimal macrophage and giant cell infiltration; and NEULL and NEU-SL, minimal to mild macrophage and giant cell infiltration. However, after subcutaneous injection of the NEU series (Table 2 and Figure 3B-G), no significant inflammation or foreign body reaction was detected, except for that after the injection of NEU-VL (mild 

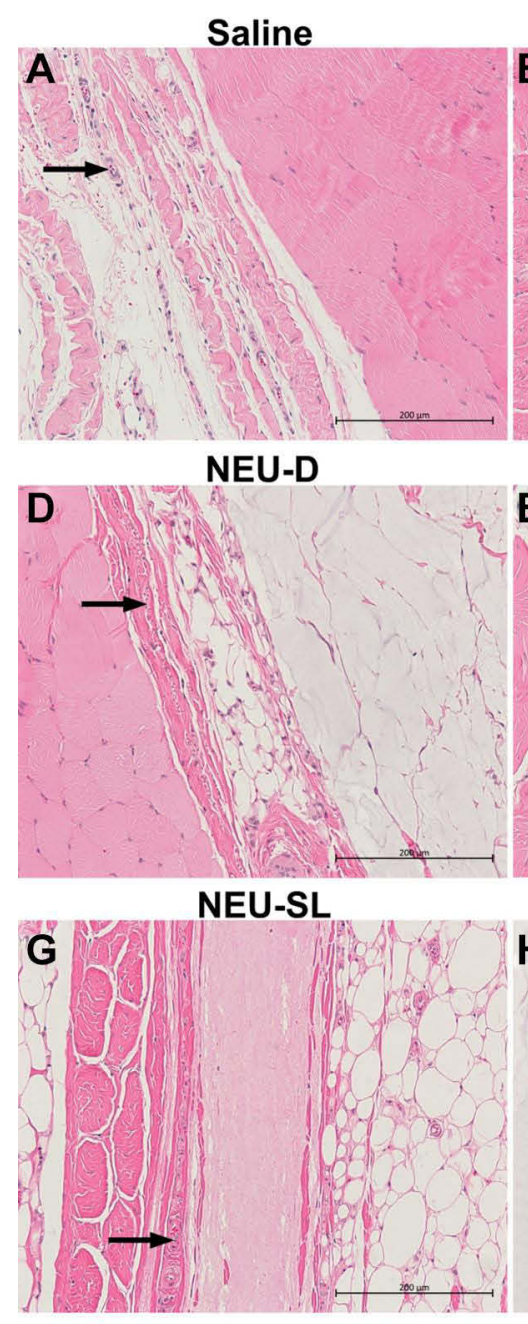

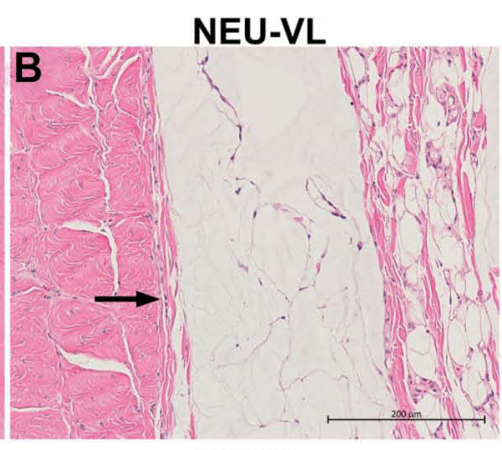

NEU-L
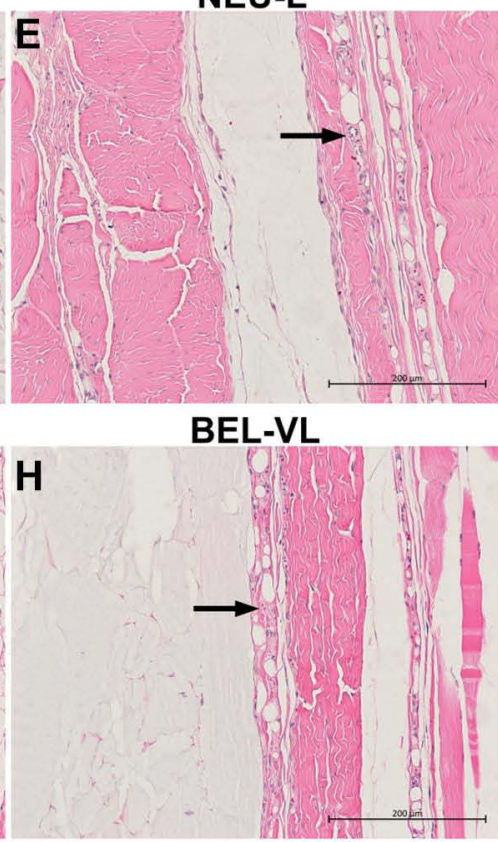

JUV-U2

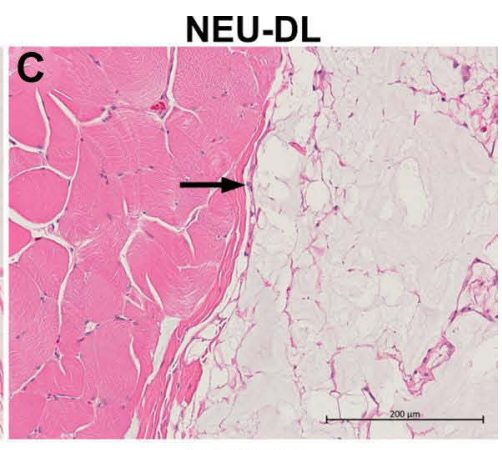

NEU-LL
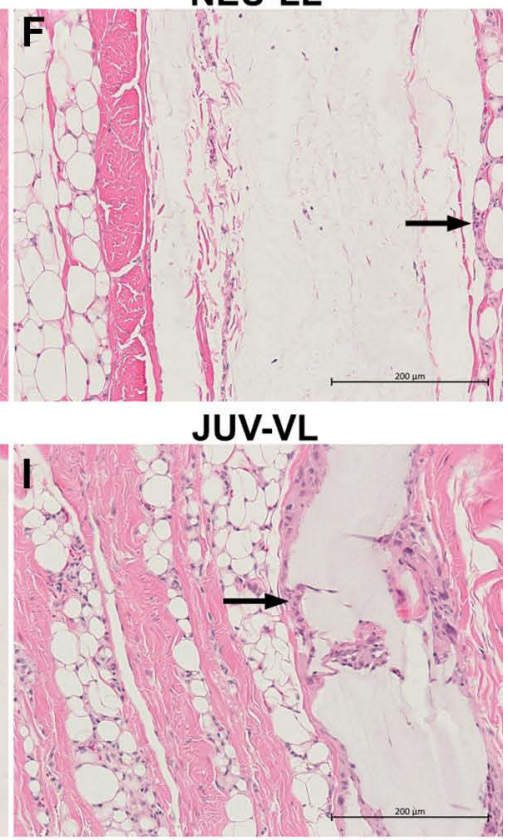

RES-LL
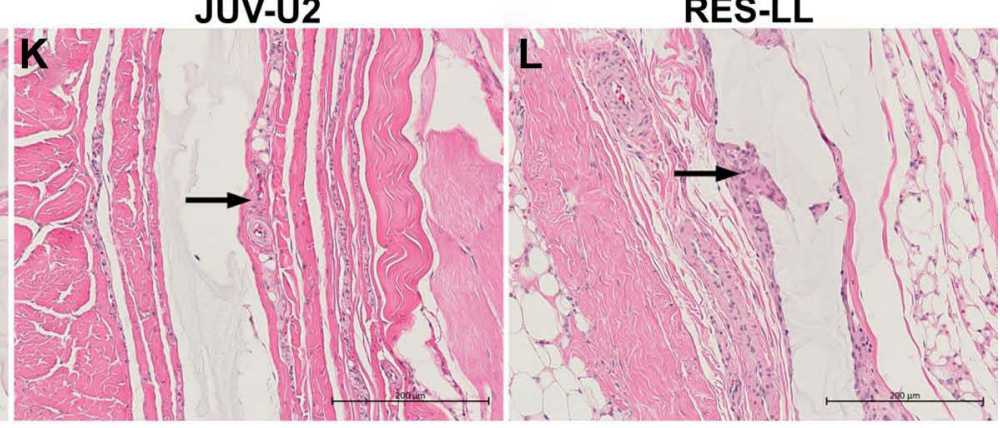

RES-S2
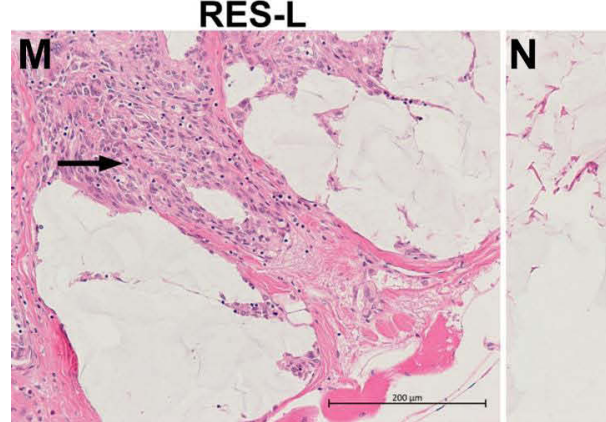

RES-S1
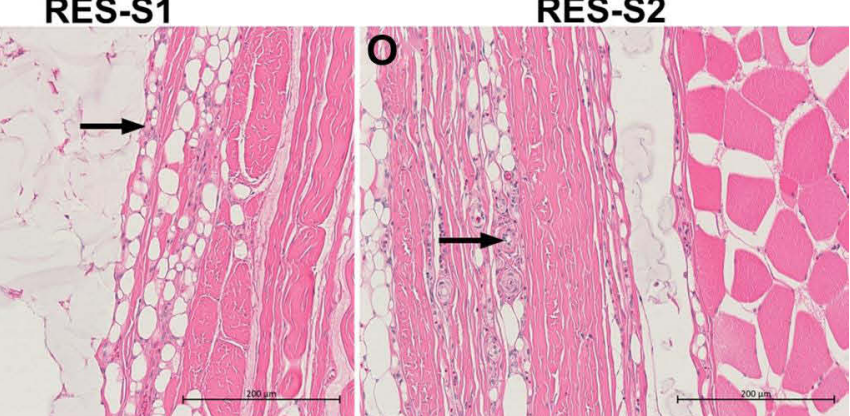

Figure 3 Hematoxylin and eosin staining at I and 4 weeks after subcutaneous injection of the saline control (A), NEU series (B-G), BEL-VL (H), JUV series (I-K), and RES series (L-O). Arrows indicate the location of the inflammatory cells. All images are shown at the same magnification $(\times 200)$. 

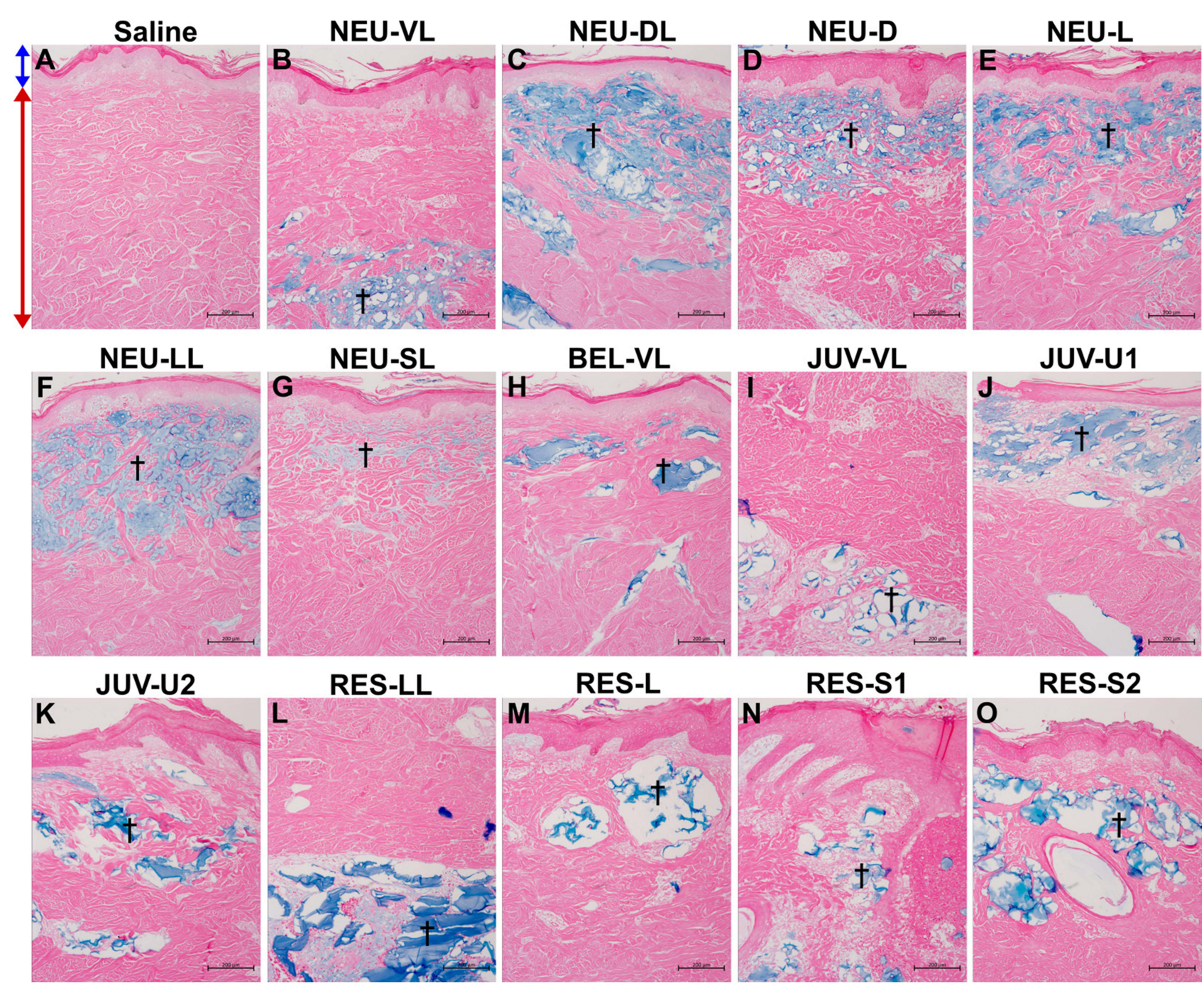

Figure 4 Alcian blue staining at I and 4 weeks after intradermal injection of the saline control (A), NEU series (B-G), BEL-VL (H), JUV series (I-K), and RES series (L-O). The NEU and BEL fillers were distributed evenly throughout the dermis as large homogeneous pools of HA material, whereas the JUV and RES fillers tended to agglomerate into smaller pools. Arrows indicate the location of the epidermis (blue) and dermis (red). Daggers indicate the presence of an amorphous basophilic substance (the injected $\mathrm{HA}$ gel) stained in blue. All images are shown at the same magnification $(\times 100)$.

macrophage and giant cell infiltration), NEU-L (mild macrophage and giant cell infiltration), and NEU-SL (minimal eosinophil infiltration).

Regarding tissue integration, most of the NEU series appeared to have slightly better integration after subcutaneous injection than after intradermal injection. After the latter, the majority of the NEU fillers were situated in the reticular layer, circumscribed, and distributed well within the dermal tissue (Figure 4B-G). After subcutaneous injection, the NEU fillers were seen as a more homogeneous mass, distributed continuously throughout the subcutis (Figure 5B-G). Only a small amount of NEU-SL remained at the injection site after 1 week of intradermal and subcutaneous injection, as shown by the faint blue coloration of the stained sections.

\section{BEL Filler (BEL-VL)}

Minimal to moderate cases of macrophage and giant cell infiltration were observed after intradermal injection of BEL-VL (Table 2 and Figure 2H), and no foreign body reaction was detected after subcutaneous injection (Table 2 and Figure $3 \mathrm{H}$ ). In the case of tissue integration, BEL-VL was separated into smaller pools that extended from the papillary layer to the reticular dermis after intradermal injection (Figure 4H). After subcutaneous injection, the distribution of BEL-VL was more homogeneous than that observed after intradermal injection (Figure 5H).

\section{JUV Series (JUV-VL, JUV-UI, and JUV-U2)}

A more severe local inflammatory response was observed for the JUV series following intradermal injection compared 

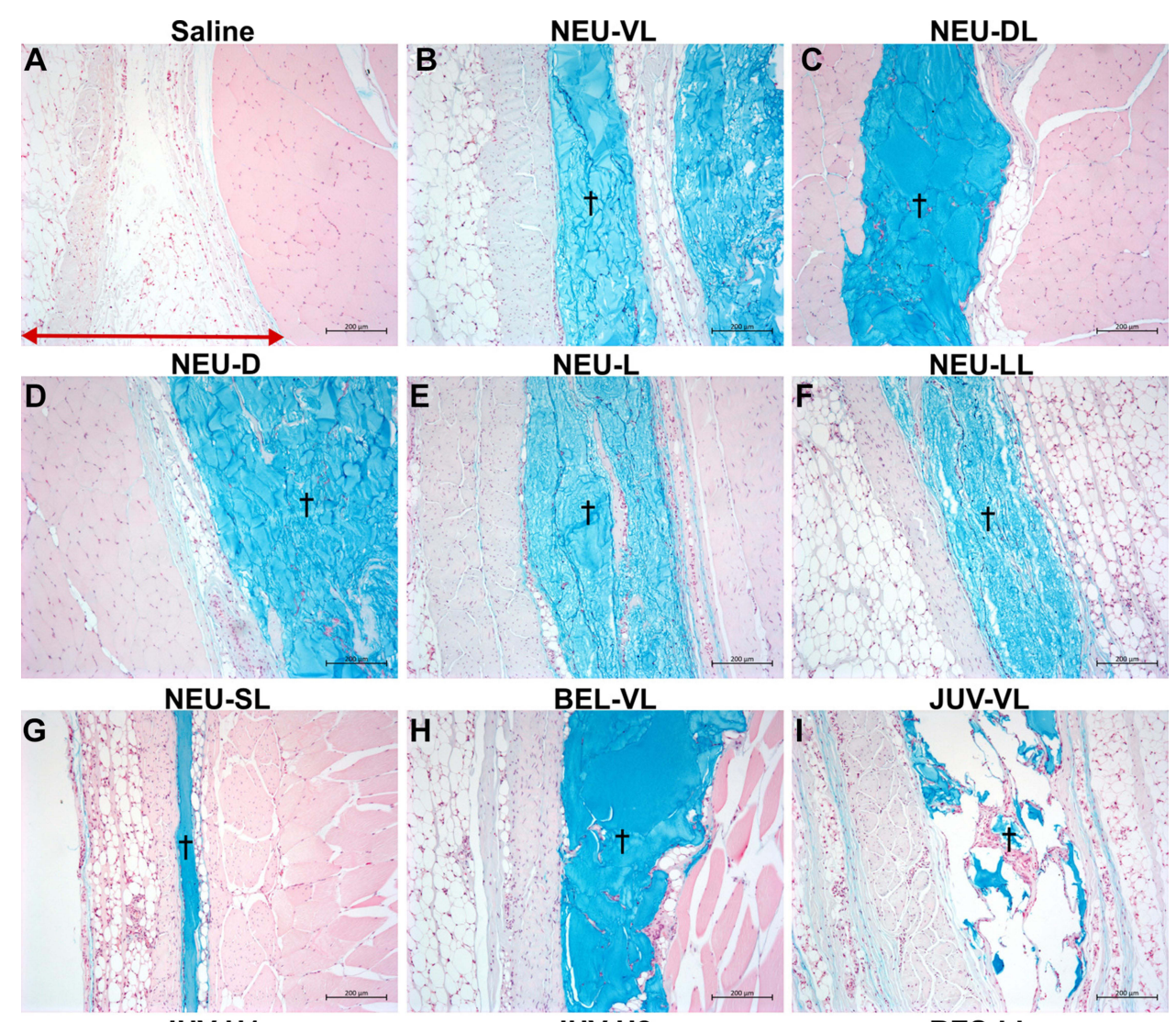

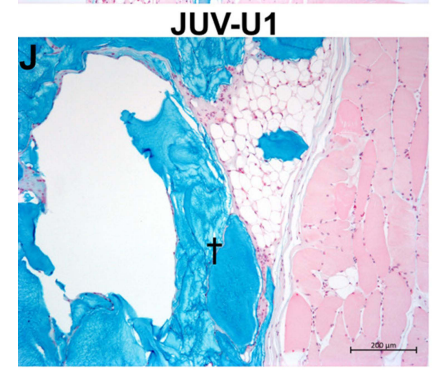

RES-L

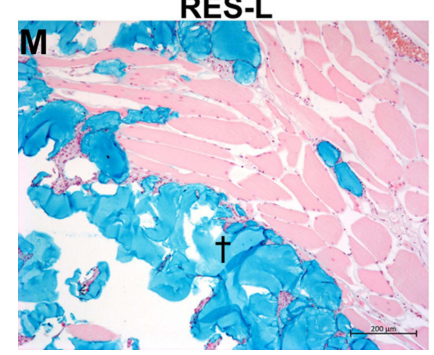

JUV-U2

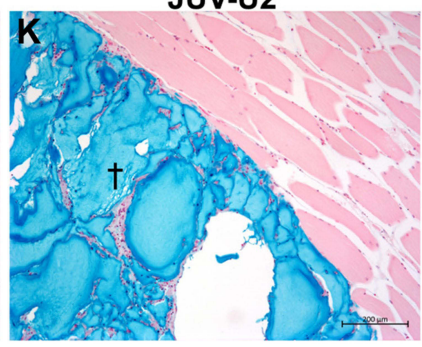

RES-S1

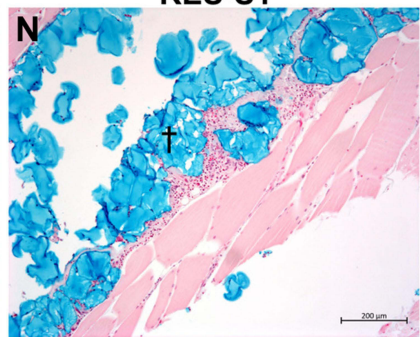

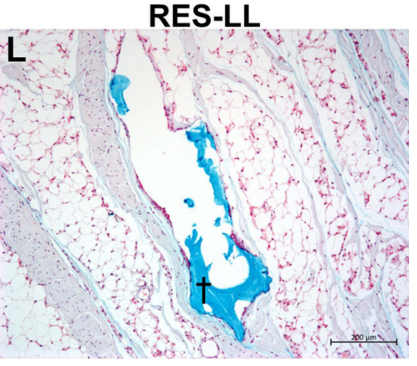

RES-S2
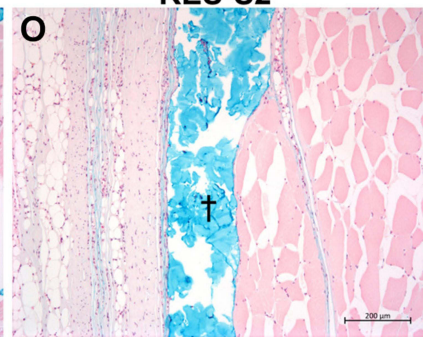

Figure 5 Alcian blue staining at I and 4 weeks after subcutaneous injection of the saline control (A), NEU series (B-G), BEL-VL (H), JUV series (I-K), and RES series (LO). The NEU and BEL fillers were distributed evenly throughout the subcutis as large homogeneous pools of HA material, whereas the JUV and RES fillers tended to agglomerate into smaller pools. The red arrow indicates the location of the subcutaneous tissue. Daggers indicate the presence of an amorphous basophilic substance (the injected HA gel) stained in blue. All images are shown at the same magnification $(\times 100)$.

to that following subcutaneous injection, and the result for each filler was as follows (Table 2 and Figure 2I-K): JUVVL, mild to moderate macrophage and giant cell infiltration and moderate purulent inflammation; JUV-U1, minimal to mild macrophage and giant cell infiltration; and JUV-U2, minimal to mild macrophage and giant cell infiltration. After subcutaneous injection, the local inflammatory responses of the JUV series were as follows (Table 2 and Figure 3I-K): JUV-VL, mild to moderate macrophage and giant cell infiltration; JUV-U1, mild macrophage and giant cell infiltration, 
Table 2 Inflammatory Cell Infiltration Score I and 4 Weeks After Intradermal and Subcutaneous Injection

\begin{tabular}{|c|c|c|c|c|c|}
\hline \multirow[t]{3}{*}{ HA Dermal Filler } & \multicolumn{5}{|c|}{ Score } \\
\hline & \multicolumn{2}{|c|}{ ID } & \multicolumn{3}{|c|}{$\mathbf{S C}^{\dagger}$} \\
\hline & Macrophage, Giant Cell & Purulent Inflammation & Macrophage, Giant Cell & Neutrophil & Fibroblast \\
\hline Saline & $0.5 \pm 0.6$ & $N / D$ & $N / D$ & $N / D$ & $N / D$ \\
\hline NEU-VL & $1.0 \pm 0.0$ & $0.8 \pm 1.5$ & $0.5 \pm 1.0$ & $N / D$ & $N / D$ \\
\hline BEL-VL & $1.8 \pm 1.5$ & $N / D$ & $N / D$ & $N / D$ & $N / D$ \\
\hline JUV-VL & $2.5 \pm 0.6^{*}$ & $0.8 \pm 1.5$ & $1.8 \pm 1.3$ & $N / D$ & $N / D$ \\
\hline NEU-DL & $1.3 \pm 0.5$ & $N / D$ & $N / D$ & $N / D$ & $N / D$ \\
\hline NEU-D & $2.0 \pm 0.8$ & $0.3 \pm 0.5$ & $N / D$ & $N / D$ & $N / D$ \\
\hline RES-LL & $2.5 \pm 0.6^{*}$ & $1.0 \pm 1.2$ & $\mathrm{I} .8 \pm 1.3$ & $\mathrm{~N} / \mathrm{D}$ & $N / D$ \\
\hline JUV-UI & $\mathrm{I} .5 \pm 0.6$ & $\mathrm{~N} / \mathrm{D}$ & $0.5 \pm 1.0$ & $\mathrm{~N} / \mathrm{D}$ & $0.5 \pm 1.0$ \\
\hline NEU-L & $0.8 \pm 0.5$ & $N / D$ & $0.5 \pm 1.0$ & $N / D$ & $N / D$ \\
\hline RES-L & $1.3 \pm 0.5$ & $0.5 \pm 0.6$ & $1.0 \pm 2.0$ & $0.8 \pm 1.5$ & $0.8 \pm 1.0$ \\
\hline JUV-U2 & $1.3 \pm 0.5$ & $N / D$ & $1.5 \pm 1.0$ & $N / D$ & $0.8 \pm 1.5$ \\
\hline NEU-LL & $1.3 \pm 0.5$ & $N / D$ & $N / D$ & $N / D$ & $N / D$ \\
\hline NEU-SL & $1.0 \pm 0.8$ & $N / D$ & $N / D$ & $\mathrm{~N} / \mathrm{D}$ & $N / D$ \\
\hline RES-SI & $1.8 \pm 0.5$ & $1.0 \pm 0.8$ & $0.5 \pm 1.0$ & $N / D$ & $N / D$ \\
\hline RES-S2 & $1.5 \pm 0.6$ & $N / D$ & $N / D$ & $N / D$ & $N / D$ \\
\hline
\end{tabular}

Notes: ${ }^{\dagger}$ In the case of subcutaneous injection, only the major histopathological evaluation parameters are shown in this table and the data for the remaining parameters are presented in Tables SI and S2. Data are expressed as mean \pm SD. *Significant difference $(p \leq 0.05)$ compared to the saline control group.

Abbreviations: HA, hyaluronic acid; ID, intradermal; SC, subcutaneous; N/D, not detected.

along with mild fibroblast proliferation; and JUV-U2, mild macrophage and giant cell infiltration, along with moderate fibroblast proliferation.

Slightly better tissue integration was observed after subcutaneous injection of the JUV series compared to that after intradermal injection. After the latter, the majority of the fillers in the JUV series formed small pools that occupied large areas within the dermis and lacked tissue integration (Figure 4I-K). After subcutaneous injection, the JUV series fillers were agglomerated into pools of HA material (defined by a darker blue lining) that were surrounded by thick rims of fibroblasts and macrophages (Figure 5I-K). Tissue sections of JUV-VL after intradermal injection and all three JUV fillers after subcutaneous injection showed large gaps caused by the displacement of tissue fibers and filler material.

\section{RES Series (RES-LL, RES-L, RES-SI, and RES-S2)}

The inflammatory responses after intradermal injection of the RES series were as follows (Table 2 and Figure 2L-O): RESLL, mild to moderate macrophage and giant cell infiltration and mild purulent inflammation; RES-L, minimal to mild macrophage and giant cell infiltration and mild purulent inflammation; RES-S1, minimal to mild macrophage and giant cell infiltration and purulent inflammation; and RES$\mathrm{S} 2$, minimal to mild macrophage and giant cell infiltration.
After subcutaneous injection, the local inflammatory responses to the RES series were as follows (Table 2 and Figure 3L-O): RES-LL, mild to moderate macrophage and giant cell infiltration; RES-L, severe macrophage and giant cell infiltration, moderate neutrophil infiltration, and minimal to mild fibroblast proliferation; RES-S1, mild macrophage and giant cell infiltration; and RES-S2, minimal cases of multiple neovascularization and local infiltration of macrophages in the muscle layer.

The distribution patterns of the RES series after subcutaneous injection were similar to those observed after intradermal injection. Tissue fibers were displaced by pools of filler material, which resulted in total disintegration (Figure $4 \mathrm{~L}-\mathrm{O}$ and Figure $5 \mathrm{~L}-\mathrm{O}$ ). A large portion of RES-L after intradermal injection and all four RES fillers after subcutaneous injection had disappeared from the tissues 1 or 4 weeks after intradermal and subcutaneous injections.

\section{Histological Comparison of Fillers According to Clinical Indication and Injection Depth Comparison of Fillers Within Categories}

Within each of the four filler categories, the JUV and RES fillers tended to have a slightly higher mean inflammatory 
cell infiltration score than the NEU fillers and BEL-VL after intradermal and subcutaneous injections (Table 2). In particular, there was a significant difference in the mean macrophage and giant cell infiltration scores in the JUVVL and RES-LL groups compared to those in the saline control group (Table 2; Mann-Whitney test, both groups $p<0.05)$. No significant difference was detected between the saline control group and the other groups.

In terms of tissue integration, fragmentation or pooling of the JUV and RES fillers was more pronounced than that of the others examined in this study. Thus, the NEU series and BELVL exhibited better tissue integration than the JUV and RES series. Additionally, regardless of the type of dermal filler, the skin responded more sensitively after intradermal injection than after subcutaneous injection, as demonstrated by the purulent inflammation observed at the dermal sites. The individual and average inflammatory cell infiltration scores for each filler group after intradermal and subcutaneous injection are presented in Tables $\mathrm{S} 1$ and $\underline{\mathrm{S}} 2$, respectively.

\section{Comparison of Fillers Between Categories}

As shown in Figure 6A and B, the mean inflammatory cell infiltration score tended to be slightly higher in the filler groups that were specifically developed to be injected into the deeper layers of the skin (NEU-VL, BEL-VL, JUV-VL, NEU-DL, NEU-D, RES-LL, and JUV-U1) than those that were developed to be injected into more superficial layers (NEU-L, RES-L, JUV-U2, NEU-LL, NEU-SL, RES-S1, and RES-S2). In particular, the fillers that were intended to be injected into the subcutis and/or deeper regions of the dermis (NEU-DL, NEU-D, RES-LL, and JUV-U1) exhibited a significantly higher mean inflammatory cell infiltration score than those that were primarily indicated for middermal injections (NEU-L, RES-L, and JUV-U2) after intradermal injection. No other significant difference was detected in the intradermal or subcutaneous studies.

In terms of tissue integration, no notable difference was observed in the distribution pattern across fillers with different clinical indications, except that the fillers that were normally injected into more superficial layers of the skin (NEU-LL, NEU-SL, RES-S1, and RES-S2) had generally disappeared from the tissue after 1 week.

\section{Discussion}

The recent trend in the development of HA dermal fillers has been to consider not only the evaluation of filler durability, but also the interaction between the tissue and the injected filler in order to appropriately select suitable fillers for the desired clinical application. However, until now, a limited number of tissue integration studies examining in vivo filler distribution patterns have investigated only a small number of HA dermal filler products using a single injection route. ${ }^{16-20}$ The present study compared the local tissue response and distribution pattern of $14 \mathrm{HA}$ dermal fillers in mini pigs using two injection routes (intradermal and subcutaneous) equivalent to those intended for clinical use of the products. Similarities in the skin structure and vascularization network between humans and mini pigs allowed reliable prediction of morphological and cellular changes as well as histological behavior of the injected fillers in humans after injection. ${ }^{36}$
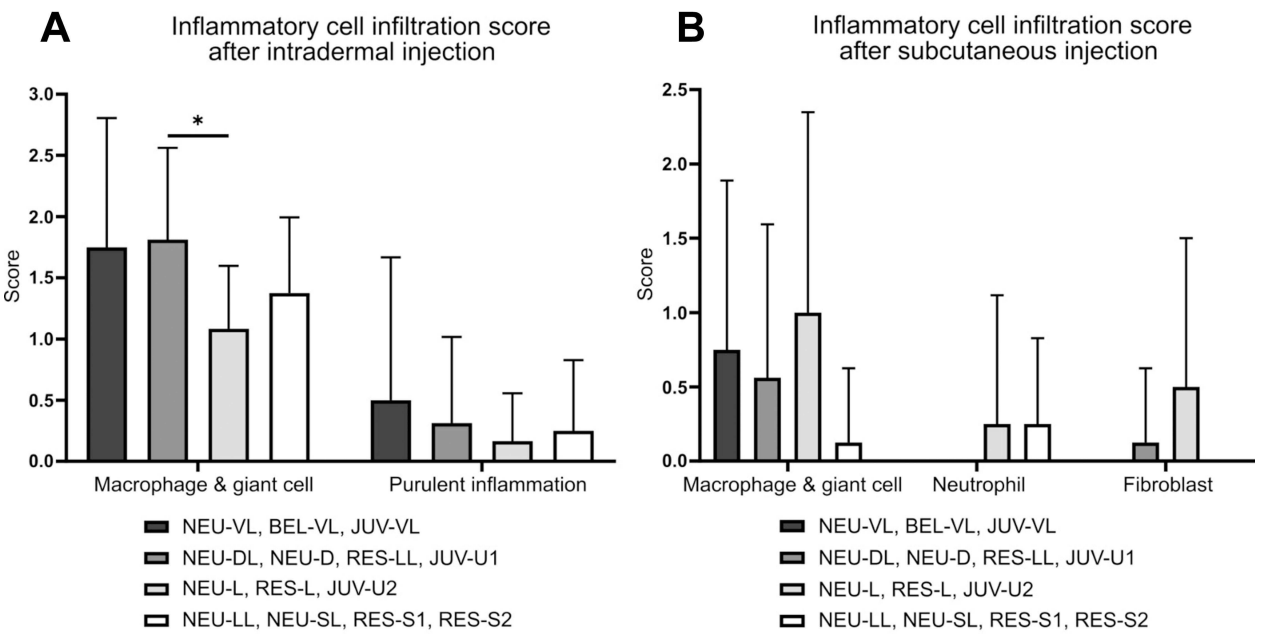

Figure 6 Inflammatory cell infiltration score (mean \pm SEM) after intradermal (A) and subcutaneous (B) injection of I4 HA dermal fillers (group comparison based on clinical indication and injection depth). *Indicates a significant difference $(p<0.01)$ in mean inflammatory cell infiltration score. 
In the present study, the degree of the local inflammatory response and tissue integration was slightly different between the intradermal and subcutaneous injection sites. Previous studies have suggested that the filler performance may be inconsistent across the different layers of the skin. ${ }^{37,38}$ Furthermore, HA dermal fillers that are injected too superficially could result in irregularities in gel distribution and the formation of visible lumps under the skin. ${ }^{39}$ Therefore, in actual clinical practice, the same HA dermal filler injected into different locations within the skin might produce different results. Moreover, superficial layers of the skin may serve as high-risk areas for uneven filler distribution; therefore, the correct placement of HA dermal filler into the appropriate region as recommended by the manufacturer is important.

Among the HA dermal fillers compared within each filler category, the NEU and BEL fillers tended to show less inflammatory cell infiltration than the JUV and RES fillers after both intradermal and subcutaneous injection. With tissue integration, the NEU and BEL fillers demonstrated even dispersion across the tissue as a homogeneous mass and were better integrated than the JUV and RES fillers. The displacement of tissue fibers and filler material in the tissue sections of JUV-VL and RES-L after intradermal injection and all JUV and RES fillers after subcutaneous injection suggest a lack of tissue integration due to formation of aggregates and minimal tissue fiber entanglements. Although NEU-SL was almost undetectable after intradermal injection, the filler did not displace tissue fibers and showed sufficient tissue fiber entanglements, suggesting that the absence of the HA material was likely due to degradation. This result was similar to that of a previously published study by Flynn and colleagues conducted in human skin, where RES was found to move into the lower dermis and subcutaneous areas with aggregation in large pools, while JUV stayed within the dermis, but retained clumping and aggregation characteristics, which resulted in a lack of integration. ${ }^{17}$ The same study also reported uniform distribution of BEL throughout the reticular dermis. High homogeneity, even distribution, and sufficient entanglement of injected HA dermal fillers within tissue fibers are often considered to equate to good tissue integration. ${ }^{16,17,20}$

The differences in tissue integration across HA dermal fillers may be attributed to variations in the type of crosslinking process used during their manufacture. All HA dermal fillers in the NEU series are manufactured as having a mono-phasic gel phase similar to BEL fillers, ${ }^{40-42}$ and is very distinct from the bi-phasic gel phase of RES fillers. $^{42,43}$ Mono-phasic HA dermal fillers consist of a mixture of high- and low-molecular weight $\mathrm{HA},{ }^{15,19}$ whereas bi-phasic HA dermal fillers consist of crosslinked HA admixed with non-crosslinked HA. ${ }^{44}$ Monophasic fillers have been reported to show higher cohesivity (ie, higher affinity between the gel molecules) and lower viscoelasticity than bi-phasic fillers. ${ }^{44,45}$ This combination of features likely allowed mono-phasic fillers (NEU series and BEL-VL) to easily occupy the small spaces between the tissue fibers while maintaining their original shape for a more homogeneous distribution. In contrast, the lower cohesivity and higher viscoelastic properties of the biphasic filler (RES series) may be attributed to its pooling characteristics. ${ }^{45,46}$ Rheological data from several other studies have demonstrated that biphasic HA gels generally have higher elastic $\left(\mathrm{G}^{\prime}\right)$ and viscous $\left(\mathrm{G}^{\prime \prime}\right)$ modulus than monophasic HA gels (Table 3). These findings suggest that the differences in tissue integration across various HA fillers may be due to the variability in cohesivity and viscoelasticity of each filler. ${ }^{47-49}$ Therefore, the specific type and degree of cross-linking, which generate the overall physicochemical properties of a gel, should be considered when selecting the right HA dermal filler for patients.

When the HA dermal fillers of different clinical indications and injection depths were compared, no significant difference was seen in tissue integration. However, the inflammatory cell infiltration tended to be greater in response to the fillers that had been specifically developed to be injected into deeper layers of the skin (subcutaneous, supraperiosteal, and/or deep dermal layer) for volume restoration and deep fold correction than for those intended to be injected into more superficial dermal layers for treatments related to fine wrinkles, skin hydrobalance, and elasticity. This finding was especially apparent in the NEU and JUV series. Generally, the different fillers in a single series have equal amounts of HA, but vary in the degree of cross-linking depending on the clinical indication. A higher degree of cross-linking meant a firmer gel. ${ }^{12,50}$ Among the HA dermal fillers within the NEU series, deeper-injection fillers (NEU-VL, NEU-DL, and NEU-D) were more firm and had a higher viscoelasticity than NEU-SL and NEU-LL (unpublished data). The viscoelastic properties of the JUV series also varied according to clinical indication. ${ }^{46,49}$ In fact, several studies have shown that the products referred to as "subcutaneous" fillers, generally had a higher $G^{\prime}$ and $G^{\prime \prime}$ than those referred to as "superficial or deep dermal" fillers 
Table 3 Characteristics of HA Dermal Fillers

\begin{tabular}{|c|c|c|c|c|c|}
\hline \multirow[t]{2}{*}{ Dermal Filler } & \multirow[t]{2}{*}{ HA Content ${ }^{\dagger}(\mathrm{mg} / \mathrm{mL})$} & \multirow[t]{2}{*}{ Cross-Linker, Type of Filler } & \multicolumn{2}{|c|}{ Rheological Findings } & \multirow[t]{2}{*}{ Reference } \\
\hline & & & G' $^{\prime}(\mathbf{P a})$ & G" (Pa) & \\
\hline NEU-VL & 20 & BDDE, monophasic & 281 & 71 & [52] \\
\hline NEU-DL & 20 & BDDE, monophasic & 129 & 28 & Unpublished data \\
\hline NEU-D & 20 & BDDE, monophasic & 173 & 33 & Unpublished data \\
\hline NEU-L & 20 & BDDE, monophasic & 57 & 24 & {$[52]$} \\
\hline NEU-LL & 20 & BDDE, monophasic & 4 & 4 & [52] \\
\hline NEU-SL & 20 & BDDE, monophasic & I & 2 & Unpublished data \\
\hline BEL-VL & 26 & BDDE, monophasic & $N / A$ & $N / A$ & Unpublished data \\
\hline JUV-VL & 20 & BDDE, monophasic & $\begin{array}{l}274 \\
284 \\
353 \\
398\end{array}$ & $\begin{array}{c}629 \\
58 \\
N / A \\
4 I\end{array}$ & $\begin{array}{l}{[49]} \\
{[52]} \\
{[54]} \\
{[53]}\end{array}$ \\
\hline JUV-UI & 24 & BDDE, monophasic & $\begin{array}{c}75 \\
244 \\
263\end{array}$ & $\begin{array}{c}177 \\
N / A \\
79\end{array}$ & $\begin{array}{l}{[49]} \\
{[54]} \\
{[53]}\end{array}$ \\
\hline JUV-U2 & 24 & BDDE, monophasic & $\begin{array}{c}28 \\
207\end{array}$ & $\begin{array}{l}73 \\
80\end{array}$ & $\begin{array}{c}{[49]} \\
{[53,54]}\end{array}$ \\
\hline RES-LL & 20 & BDDE, biphasic & $\begin{array}{c}411 \\
\text { Approx. } 540 \\
545\end{array}$ & $\begin{array}{c}199 \\
\text { Approx. } 70 \\
\text { N/A }\end{array}$ & $\begin{array}{l}{[52]} \\
{[55]} \\
{[54]}\end{array}$ \\
\hline RES-L & 20 & BDDE, biphasic & $\begin{array}{c}349 \\
\text { Approx. } 540 \\
544 \\
864\end{array}$ & $\begin{array}{c}145 \\
\text { Approx. } 100 \\
\text { N/A } \\
\text { I85 }\end{array}$ & $\begin{array}{l}{[52]} \\
{[55]} \\
{[54]} \\
{[53]}\end{array}$ \\
\hline RES-SI & 20 & BDDE, biphasic & $\mathrm{N} / \mathrm{A}$ & N/A & Not published \\
\hline RES-S2 & 12 & BDDE, biphasic & Approx. 30 & Approx. 10 & [55] \\
\hline
\end{tabular}

Notes: ${ }^{\dagger}$ From the package insert.

Abbreviations: HA, hyaluronic acid; BDDE, I.4-butanediol diglycidyl ether; G', elastic modulus; G”, viscous modulus; Pa, pascal; N/A, not available; Approx., approximately.

(Table 3). High viscoelasticity, commonly associated with deep injection gels, seems to facilitate a stronger immune response, presumably by exerting more stress on the surrounding tissues. Therefore, greater precautions should be taken when using HA dermal fillers designated for deeper volumizing injections.

The main limitation of the present study was that only one mini pig was used to evaluate each injection route (intradermal and subcutaneous), and the injection sites were examined at a single time point ( 1 or 4 weeks after injection). Although foreign body reactions and inflammatory cell infiltration were observed in some of the HA dermal fillers, the tissue responses could recover with time. ${ }^{51}$ Therefore, the short-term tissue responses may not represent the overall biocompatibility or safety. Further investigation is warranted to determine the long-term effects of HA dermal fillers on the local tissue response and integration.

The evaluation of tissue integration in the present study was subjected to the pathologist's judgement following only the specific features of tissue integration mentioned in other studies that have assessed this parameter in HA dermal fillers. ${ }^{17,20}$ Thus, a more thorough assessment of filler tissue integration using a quantitative approach that employs visual scoring or image analysis following a specific evaluation criteria such as those described by Duraget and colleagues ${ }^{16}$ is recommended for future studies. 


\section{Conclusion}

This is the first study to provide a descriptive data on tissue integration of 14 HA dermal fillers following intradermal and subcutaneous injections in mini pigs. The results not only suggest that the local inflammatory response and tissue integration may differ between HA dermal filler products, but also indicate that the parameters may differ according to the recommended clinical indication and injection depth of the products. These differences may be influenced by factors, such as the type and degree of cross-linking and the distinctive physicochemical properties of each HA dermal filler. Further research on the actual physicochemical properties of HA dermal fillers and their starting material (molecular weight and cross-linking degree) should provide better insights into whether there is a direct relationship between the factors and the safety and tissue integration of fillers. In conclusion, the present study provided an evidence-based scientific rationale for plastic surgeons to objectively categorize HA dermal fillers, choose the best suitable filler products, and reliably predict their clinical behavior, in terms of interaction with the tissue following injection into the appropriate region.

\section{Acknowledgments}

This study was supported by the Technology Innovation Program, establishment of risk management platform with aim of reduce attrition of new drugs and its service [grant number: 10067737, 2016], funded by the Ministry of Trade, Industry \& Energy in Republic of Korea (WCS).

\section{Disclosure}

M-S. Choi, S.S. Kwak, J.H. Kim, M-S. Park, C-H Rhee, G-H Yang, and W-H Kang are employees of Medytox, Inc., a biopharmaceutical company based in South Korea. G-H Yang is the vice president of Medytox, Inc. The authors report no other conflicts of interest associated with this work.

\section{References}

1. Mero A, Campisi M. Hyaluronic Acid Bioconjugates for the Delivery of Bioactive Molecules. Polymers. 2014;6(2):346-369. doi:10.3390/ polym6020346

2. Gold MH. Use of hyaluronic acid fillers for the treatment of the aging face. Clin Interv Aging. 2007;2(3):369-376. doi:10.2147/CIA.S1244

3. Song JE, Kim MJ, Yoon H, et al. Effect of hyaluronic acid (HA) in a HA/PLGA scaffold on annulus fibrosus regeneration: in vivo tests. Macromolecular Res. 2013;21(10):1075-1082. doi:10.1007/s13233013-1137-z
4. Valachova K, Svik K, Biro C, et al. Impact of Ergothioneine, Hercynine, and Histidine on Oxidative Degradation of Hyaluronan and Wound Healing. Polymers. 2020;13:1. doi:10.3390/polym13010095

5. Zamboni F, Keays M, Hayes S, et al. Enhanced cell viability in hyaluronic acid coated poly(lactic-co-glycolic acid) porous scaffolds within microfluidic channels. Int J Pharm. 2017;532(1):595-602. doi:10.1016/j.ijpharm.2017.09.053

6. Papakonstantinou E, Roth M, Karakiulakis G. Hyaluronic acid: a key molecule in skin aging. Dermatoendocrinol. 2012;4(3):253-258. doi:10.4161/derm. 21923

7. Khunmanee S, Jeong Y, Park H. Crosslinking method of hyaluronic-based hydrogel for biomedical applications. J Tissue Eng. 2017;8:2041731417726464. doi:10.1177/2041731417726464

8. Zamboni F, Ryan E, Culebras M, Collins MN. Labile crosslinked hyaluronic acid via urethane formation using bis(beta-isocyanatoethyl) disulphide with tuneable physicochemical and immunomodulatory properties. Carbohydr Polym. 2020;245:116501. doi:10.1016/j.carbpol.2020.116501

9. Zamboni F, Okoroafor C, Ryan MP, et al. On the bacteriostatic activity of hyaluronic acid composite films. Carbohydr Polym. 2021;260:117803. doi:10.1016/j.carbpol.2021.117803

10. De Boulle K, Glogau R, Kono T, et al. A review of the metabolism of 1,4-butanediol diglycidyl ether-crosslinked hyaluronic acid dermal fillers. Dermatol Surg. 2013;39(12):1758-1766. doi:10.1111/ dsu. 12301

11. Walker K, Basehore BM, Goyal A, Bansal P, Zito PM. Hyaluronic Acid. Treasure Island (FL): StatPearls; 2021.

12. Segura S, Anthonioz L, Fuchez F, Herbage B. A complete range of hyaluronic acid filler with distinctive physical properties specifically designed for optimal tissue adaptations. J Drugs Dermatol. 2012;11(1 Suppl):s5-8.

13. Merola F, Scrima M, Melito C, et al. A novel animal model for residence time evaluation of injectable hyaluronic acid-based fillers using high-frequency ultrasound-based approach. Clin Cosmet Investig Dermatol. 2018;11:339-346. doi:10.2147/CCID.S156740

14. Mochizuki M, Aoi N, Gonda K, Hirabayashi S, Komuro Y. Evaluation of the In Vivo Kinetics and Biostimulatory Effects of Subcutaneously Injected Hyaluronic Acid Filler. Plast Reconstr Surg. 2018;142(1):112-121. doi:10.1097/PRS.0000000000004496

15. Ryu HJ, Kwak SS, Rhee CH, Yang GH, Yun HY, Kang WH. ModelBased Prediction to Evaluate Residence Time of Hyaluronic Acid Based Dermal Fillers. Pharmaceutics. 2021;13:2. doi:10.3390/ pharmaceutics13020133

16. Dugaret AS, Bertino B, Gauthier B, et al. An innovative method to quantitate tissue integration of hyaluronic acid-based dermal fillers. Skin Res Technol. 2018;24(3):423-431. doi:10.1111/srt.12445

17. Flynn TC, Sarazin D, Bezzola A, Terrani C, Micheels P. Comparative histology of intradermal implantation of mono and biphasic hyaluronic acid fillers. Dermatol Surg. 2011;37(5):637-643. doi:10.1111/ j.1524-4725.2010.01852.x

18. Micheels P, Besse S, Flynn TC, Sarazin D, Elbaz Y. Superficial dermal injection of hyaluronic acid soft tissue fillers: comparative ultrasound study. Dermatol Surg. 2012;38(7 Pt 2):1162-1169. doi:10.1111/j.1524-4725.2012.02471.x

19. Micheels P, Besse S, Sarazin D. Two Crosslinking Technologies for Superficial Reticular Dermis Injection: a Comparative Ultrasound and Histologic Study. J Clin Aesthet Dermatol. 2017;10(1):29-36.

20. Tran C, Carraux P, Micheels P, Kaya G, Salomon D. In vivo bio-integration of three hyaluronic acid fillers in human skin: a histological study. Dermatology. 2014;228(1):47-54. doi:10.1159/ 000354384

21. Medytox, Inc. Neuramis ${ }^{\circledR}$ Volume Lidocaine [Package Insert]. Republic of Korea: Medytox, Inc; 2020.

22. Medytox, Inc. Neuramis ${ }^{\circledR}$ Deep Lidocaine [Package Insert]. Republic of Korea: Medytox, Inc; 2020. 
23. Medytox, Inc. Neuramis ${ }^{\circledR}$ Deep [Package Insert]. Republic of Korea: Medytox, Inc; 2015.

24. Medytox, Inc. Neuramis ${ }^{\circledR}$ Lidocaine [Package Insert]. Republic of Korea: Medytox, Inc; 2015.

25. Medytox, Inc. Neuramis ${ }^{\circledR}$ Light Lidocaine [Package Insert]. Republic of Korea: Medytox, Inc; 2014.

26. Medytox, Inc. Neuramis ${ }^{\circledR}$ Skin Lidocaine [Package Insert]. Republic of Korea: Medytox, Inc; 2017.

27. Merz Aesthetics. Belotero ${ }^{\circledR}$ Volume Lidocaine [Package Insert]. Switzerland: Merz Aesthetics; 2015.

28. Allergan, Inc. Juvéderm ${ }^{\circledR}$ VOLUMA with Lidocaine [Package Insert]. Pringy, France: Allergan, Inc; 2015.

29. Allergan, Inc. Juvéderm ${ }^{\circledR}$ ULTRA PLUS XC [Package Insert]. Pringy, France: Allergan, Inc; 2016.

30. Allergan, Inc. Juvéderm ${ }^{\circledR}$ ULTRA XC [Package Insert]. Pringy, France: Allergan, Inc; 2016.

31. Q-Med AB. Restylane ${ }^{\circledR}$ LYFT with Lidocaine [Package Insert]. Uppsala, Sweden: Q-Med AB; 2018.

32. Q-Med AB. Restylane ${ }^{\circledR}$ Lidocaine [Package Insert]. Uppsala, Sweden: Q-Med AB; 2016.

33. Q-Med AB. Restylane ${ }^{\circledR}$ SKINBOOSTERSTM VITAL Lidocaine [Package Insert]. Uppsala, Sweden: Q-Med AB; 2018.

34. Q-Med AB. Restylane ${ }^{\circledR}$ SKINBOOSTERS ${ }^{\mathrm{TM}}$ VITAL LIGHT Lidocaine [Package Insert]. Uppsala, Sweden: Q-Med AB; 2016.

35. ISO 10993-6. Biological Evaluation of Medical Devices. Part 6: Tests for Local Effects After Implantation. International Organization for Standardization; 2016.

36. Summerfield A, Meurens F, Ricklin ME. The immunology of the porcine skin and its value as a model for human skin. Mol Immunol. 2015;66(1):14-21. doi:10.1016/j.molimm.2014.10.023

37. Rauso R. Evaluation of different depth injections of reticulated hyaluronic acid fillers with different concentration. J Clin Cosmet Dermatol. 2018;2:1.

38. Williams S, Tamburic S, Stensvik H, Weber M. Changes in skin physiology and clinical appearance after microdroplet placement of hyaluronic acid in aging hands. J Cosmet Dermatol. 2009;8 (3):216-225. doi:10.1111/j.1473-2165.2009.00447.x

39. Cheng LY, Sun XM, Tang MY, Jin R, Cui WG, Zhang YG. An update review on recent skin fillers. Plast Aesthet Res. 2016;3:92-99. doi:10.20517/2347-9264.2015.124

40. Belmontesi M, De Angelis F, Di Gregorio C, et al. Injectable Non-Animal Stabilized Hyaluronic Acid as a Skin Quality Booster: an Expert Panel Consensus. J Drugs Dermatol. 2018;17(1):83-88.

41. Joo HJ, Woo YJ, Kim JE, Kim BJ, Kang H. A randomized clinical trial to evaluate the efficacy and safety of lidocaine-containing monophasic hyaluronic acid filler for nasolabial folds. Plast Reconstr Surg. 2016;137(3):799-808. doi:10.1097/01.prs.0000479965.14775.f0

42. Paap MK, Silkiss RZ. The interaction between hyaluronidase and hyaluronic acid gel fillers - a review of the literature and comparative analysis. Plast Aesthet Res. 2020;7:36.

43. Pak C, Park J, Hong J, et al. III, Randomized, Multi-Center, Double-Masked, Matched-Pairs, Active-Controlled Trial to Compare the Efficacy and Safety between Neuramis Deep and Restylane in the Correction of Nasolabial Folds. Arch Plast Surg. 2015;42(6):721-728. doi:10.5999/aps.2015.42.6.721
44. Prasetyo AD, Prager W, Rubin MG, Moretti EA, Nikolis A. Hyaluronic acid fillers with cohesive polydensified matrix for soft-tissue augmentation and rejuvenation: a literature review. Clin Cosmet Investig Dermatol. 2016;9:257-280. doi:10.2147/CCID. S106551

45. Salti G, Fundaro SP. Evaluation of the Rheologic and Physicochemical Properties of a Novel Hyaluronic Acid Filler Range with eXcellent Three-Dimensional Reticulation (XTR) Technology. Polymers. 2020;12:8. doi:10.3390/polym12081644

46. Stocks D, Sundaram H, Michaels J, Durrani MJ, Wortzman MS, Nelson DB. Rheological evaluation of the physical properties of hyaluronic acid dermal fillers. $J$ Drugs Dermatol. 2011;10 (9):974-980.

47. Molliard SG, Bétemps JB, Hadjab B, Topchian D, Micheels P, Salomon D. Key rheological properties of hyaluronic acid fillers: from tissue integration to product degradation. Plast Aesthet Res. 2018;5:17. doi:10.20517/2347-9264.2018.10

48. Sundaram H, Rohrich RJ, Liew S, et al. Cohesivity of Hyaluronic Acid Fillers: development and Clinical Implications of a Novel Assay, Pilot Validation with a Five-Point Grading Scale, and Evaluation of Six U.S. Food and Drug Administration-Approved Fillers. Plast Reconstr Surg. 2015;136(4):678-686. doi:10.1097/ PRS.0000000000001638

49. Sundaram H, Voigts B, Beer K, Meland M. Comparison of the rheological properties of viscosity and elasticity in two categories of soft tissue fillers: calcium hydroxylapatite and hyaluronic acid. Dermatol Surg. 2010;36(Suppl 3):1859-1865. doi:10.1111/j.15244725.2010.01743.x

50. Kablik J, Monheit GD, Yu L, Chang G, Gershkovich J. Comparative physical properties of hyaluronic acid dermal fillers. Dermatol Surg. 2009;35(Suppl 1):302-312. doi:10.1111/j.1524-4725.2008.01046.x

51. Lemperle G, Morhenn V, Charrier U. Human histology and persistence of various injectable filler substances for soft tissue augmentation. Aesthetic Plast Surg. 2003;27(5):354-366. doi:10.1007/s00266-003-3022-1

52. Lee W, Hwang SG, Oh W, Kim CY, Lee JL, Yang EJ. Practical Guidelines for Hyaluronic Acid Soft-Tissue Filler Use in Facial Rejuvenation. Dermatol Surg. 2020;46(1):41-49. doi:10.1097/ DSS.0000000000001858

53. Pierre S, Liew S, Bernardin A. Basics of dermal filler rheology. Dermatol Surg. 2015;41(Suppl 1):S120-126. doi:10.1097/ DSS.0000000000000334

54. Rohrich RJ, Bartlett EL, Dayan E. Practical Approach and Safety of Hyaluronic Acid Fillers. Plast Reconstr Surg Glob Open. 2019;7(6): e2172. doi:10.1097/GOX.0000000000002172

55. Edsman KLM, Ohrlund A. Cohesion of Hyaluronic Acid Fillers: correlation Between Cohesion and Other Physicochemical Properties. Dermatol Surg. 2018;44(4):557-562. doi:10.1097/ DSS. 0000000000001370
Clinical, Cosmetic and Investigational Dermatology is an international, peer-reviewed, open access, online journal that focuses on the latest clinical and experimental research in all aspects of skin disease and cosmetic interventions. This journal is indexed on CAS.
The manuscript management system is completely online and includes a very quick and fair peer-review system, which is all easy to use. Visit http://www.dovepress.com/testimonials.php to read real quotes from published authors. 